\title{
Dictogloss as an Interactive Method of Teaching Listening Comprehension
}

\author{
to L2 Learners
}

\author{
Zorana Vasiljevic \\ Faculty of Literature, Bunkyo University \\ 3337 Minami Ogishima, Koshigaya City, Saitama 343-8511, Japan \\ tel: 81-48-974-8811 E-mail: zorana@koshigaya.bunkyo.ac.jp
}

\begin{abstract}
The article describes how the dictogloss method and cooperative learning can be combined to promote the development of listening and speaking skills of second language learners. The paper begins with an outline of the dictogloss procedure and the theoretical background behind it. The procedures for conducting a dictogloss-based listening class are then described in great detail. Finally, the potential advantages of this method as well as concerns about its implementation are discussed.
\end{abstract}

Keywords: Dictogloss, Listening and Speaking Instruction, Cooperative Learning, Learner Autonomy

\section{Background}

Listening is one of the most important language skills. Feyten (1991) claims that more than $45 \%$ of communicating time is spent listening, which clearly shows how important this skill is in overall language ability. Traditionally, listening skills have been taught in isolation or they were sometimes combined with speaking tasks. However, the nature of real-life interaction and the limited time most learners have at their disposal are strong arguments in favour of the integration of the four skills and for different modes of language practice. This paper will describe the methodology for teaching a listening class based on the dictogloss approach, which offers a bridge between different language skills and promotes collaborative learning in the classroom

Dictogloss is a classroom dictation activity where learners listen to a passage, note down key words and then work together to create a reconstructed version of the text. It was originally introduced by Ruth Wajnryb (1990) as an alternative method of teaching grammar. The original dictogloss procedure consists of four basic steps:

a. Warm-up when the learners find out about the topic and do some preparatory vocabulary work.

b. Dictation when the learners listen to the text read at a normal speed by the teacher and take fragmentary notes. The learners will typically hear the text twice. The first time the teacher reads the text, the students just listen but do not write. The second time, the students take notes.

c. Reconstruction when the learners work together in small groups to reconstruct a version of the text from their shared resources.

d. Analysis and correction when students analyse and compare their text with the reconstructions of other students and the original text and make the necessary corrections (Wajnryb, 1990).

Wajnrub argues that this method gives students a more precise understanding of English grammar than do other approaches and consequently leads to higher accuracy in language use. Compared to other more traditional approaches to teaching grammar the value of dictogloss is in its interactive approach to language learning. Text reconstruction promotes both the negotiation of meaning and the negotiation of form. It is a co-operative endeavour which forces learners to stay actively engaged in the learning process. "Through active learner involvement students come to confront their own strengths and weaknesses in English language use. In so doing, they find out what they do not know, then they find out what they need to know." (Wajnryb, 1990:10)

Wajnrub also argues that this integration of testing and teaching stimulates the learners' motivation. Rather than having the teacher select specific grammatical features and have the students practice them, the students identify their grammar problems and the teacher teaches in response to their needs.

Dictogloss has been the subject of a number of studies and commentaries, which have, in most part supported the use of the technique (Swain \& Miccoli, 1994; Swain \& Lapkin, 1998; Storch, 1998; Nabei, 1996; Lim \& Jacobs, 2001). The supporters of the method pointed out that dictogloss are a multiple skills and systems activity. Learners practice 
listening, writing and speaking and rely on their knowledge of semantic, syntactic and discourse systems of the target language to complete the task. However, the focus of these studies remains on grammatical competence. Improvements in listening comprehension or students' note-taking skills are seen as by-products of the method rather than its objectives.

This paper will take a different approach. Rather than looking at listening improvements as beneficial side-effects of the grammar-focused instruction, the article will describe a listening class centered around the dictogloss procedure. The benefits of the approach and some concerns regarding its implementation will be discussed. It is hoped that the description of the procedure and the insights from the literature on cooperative learning will help teachers use the dictogloss method more effectively.

\section{Placing the dictogloss procedure in a listening context}

Listening requires the utilisation of both systemic and schematic knowledge (Widdowson, 1983; Buck, 2001). In order to interpret the discourse, the listener must have a sufficient knowledge of the language system (i.e. an understanding of the phonological, syntactic and semantic aspect knowledge) as well as general knowledge of the world.

At the initial stages of language learning the primary goal of listening instruction is to help learners understand the acoustic input. Listening activities are designed to give the learner practice in identifying correctly different sounds, sound-combinations and intonation patterns. As the learners' proficiency increases, meaning based activities become more important.

Meaning based activities can be divided into two broad categories: (1) activities that assess direct meaning comprehension and those that measure inferred meaning comprehension (Mewald, Gassner \& Sigott, 2007). Direct meaning comprehension means the understanding of surface information and facts that are explicitly stated in the input text. Some examples are listening for gist, listening for main points and listening for specific information.

Inferred meaning comprehension includes implicit understanding and drawing inferences from input texts. The information required is not clearly stated, and the listener must go beyond the surface information to see other meanings which are not explicitly stated in the text. Some examples of this type of listening are inferring a speaker's intention or attitude towards a topic, relating utterances to their social and situational contexts, recognising the communicative function of utterances, and so on.

The dictogloss listening procedure falls into the first category. This is important as the type of listening activity has direct implications for the selection of the listening materials.

\section{Material selection}

Although most real-life listening is spontaneous and colloquial in character (Ur, 1998), there are situations when we have to listen to uninterrupted speech for a longer a period of time. Some examples are listening to academic lectures or stories. The dictogloss method is generally more suitable for this kind of material than dialogues or instructions. Transactional texts (i.e. texts where the primary purpose is to communicate information) are easier to reconstruct than interactional passages where the purpose is to maintain social relationships.

The passages should not be too long, so that students can finish reconstruction and receive feedback in the same lesson. In my experience, about 2 minutes of this kind of listening is plenty for intermediate-level classes.

Another decision that teachers need to make is whether to use authentic materials or prepared texts. Natural speech is linguistically different from writing. Acoustic input is characterized by features such as phonological modification, word stress and intonation, hesitation, loosely or poorly organized ideas and fragments of language with false starts, restatements, vocabulary repair and even grammatically incorrect sentences, and so on (Buck, 2001). Learners also need to be able to process word meanings, syntax and discourse features. Therefore, it is important that dictogloss texts are carefully selected.

Dictogloss works better with prepared listening passages. As Ur (1998) points out, the use of authentic unrehearsed discourse has two main drawbacks. First, the speed of such recordings is ungraded and the language may be difficult, making the recordings suitable only for the highest levels. Second, when listening to recordings of natural conversations it is very difficult to understand the situation, identify the different voices and cope with frequent overlaps. Teachers may want to take advantage of published recordings in listening comprehension textbooks or, if those are not available, prepare the text themselves and read it to their students. For reasons of consistency, however, it is preferable that students listen to a recording rather than a teacher-read text.

The speed and complexity of the input will have a significant effect on the learners' ability to process the text. As a general rule, the texts should be at or below the students' current proficiency level, although they may include some new vocabulary. Listening comprehension requires language processing to be almost automatic. As the speech rate gets faster, students have to pay more attention to lexical and grammatical processing and less attention to the interpretation of the meaning. They are likely to miss parts of the text and consequently fail to understand the message (Buck, 2001). 
Another factor to consider is the explicitness of discourse markers. As Olsen and Huckin (1990) observe, ESL students can sometimes understand all the words in the text, and still fail to understand the main points. The understanding of academic lectures was found to depend less on the meaning of individual sentences, and more on their inter-relatedness and the structure of the whole text (Dunkel \& Davis, 1994). Clear discourse markers can significantly improve the comprehension of L2 listeners (Chaudron \& Richards, 1986).

Therefore, listening materials should be graded. For lower level students, or students who are not used to the dictogloss approach, shorter and slower texts with the micro- and macro-structure explicitly signaled should be selected. However, as the learners' listening skills improve and they learn to process language more automatically, teachers should expose them to more realistic texts (e.g. spontaneous speech), which preserve the characteristics of the oral language. As redundancy was found to benefit higher-ability students more than lower ability ones (Chiang \& Dunkel, 1992), more proficient learners should be exposed to texts which include repetition and paraphrasing. (A sample text suitable for low intermediate learners is available in the Appendix.)

\section{Dictogloss listening procedure}

The basic steps in dictogloss listening classes are the same as those outlined by Wajnrub (1990) for the purpose of grammar teaching. There are four stages: preparation, listening, reconstruction and analysis and correction. Each stage will now be described in more detail. (Sample materials for each stage are available in the Appendix).

\subsection{Preparation}

The purpose of the preparation stage is to make students more receptive to the listening passage. Listening is a dynamic process where the listeners construct meaning based on the interplay of background knowledge and the new concepts presented in the text. In other words, listening comprehension requires both topical and linguistic knowledge. Teachers can facilitate this process by providing background information and helping students with unfamiliar language. The purpose of the preparation stage is therefore twofold: it should give the learners a topical warm-up as well as familiarize them with vocabulary that will appear in the text.

\subsubsection{Topical warm-up}

The topical warm-up is important as it enables learners to activate their background knowledge. Knowledge of the content helps listeners interpret the message correctly. This is because understanding presupposes an interaction between the knowledge stored in the semantic memory and perceptual experience (Kintsch, 1977). As learners often have insufficient knowledge of the linguistic system, content and textual schemata may be crucial for an understanding of the text.

Topical preparation is particularly important when the texts may introduce culturally unfamiliar concepts. Background knowledge is represented in human memory through scripts, that is, sets of expectations people have about general concepts, places, situations, actions and their sequences. Scripts play an important role in human information processing and they tend to be culture-bound (Buck, 2001). Therefore, the extent to which the listener may share background knowledge with the speakers is an important issue to consider at the preparation stage.

One simple way to introduce the topic is to give students some topical questions for discussion. For example, if listening is going to be about food, asking students to discuss questions such as What kind of food do you like? How healthy are your eating habits? Do you prefer to eat out or at home? What is the most unusual food you have tried? and so on can be a good warm-up activity. Questions should gradually draw the students' attention to the specific topic of the listening extract. For example, for the Model Lesson included in the Appendix, where the topic is Moroccan food, some good pre-listening questions are Do you like ethnic food? What do you know about eating and drinking habits in Muslim countries? Where does couscous come from? Teachers may also bring some visual aids (e.g. photos, pictures, graphs, objects) relevant to the topic and have students predict what the listening may be about, which may be about to help them develop their top-down processing skills.

\subsubsection{Vocabulary preparation}

Insufficient vocabulary knowledge is a frequent cause of listening comprehension problems. Due to limited vocabulary size and problems with the perception of acoustic forms, learners often experience difficulties in processing audio input. Learners may not know the words that appear in the spoken discourse, or they may not be able to recognize them in the strings of connected speech. Failure to understand the input correctly also means that learners will have difficulties anticipating the upcoming discourse. Studies from L1 showed that native speakers use context to make predictions about the utterances that are likely to follow (Nattinger \& DeCarrico, 1992; Ur,1998). If the listener knows how the sentence is likely to finish, the closing words become redundant and he/she can focus on the next significant piece of information. As language learners often do not have enough linguistic knowledge, they cannot take advantage of contextual redundancy in the way that native speakers can. More mental effort is needed to process information which means that less information can be stored at one time in the short-term memory. As Nattinger and DeCarrico (1992) 
point out, such a reduction in storage capacity means that less linguistic data can be analyzed simultaneously, thus impeding the comprehension process.

Sufficient vocabulary preparation is also important because lexical knowledge entails background knowledge (Rumelhart, 1980). The more a learner knows about a word, the more he/she is likely to be aware of the semantic links in the structure of a text and consequently the more likely he/she is to activate the relevant background knowledge crucial for text comprehension. Recognition of word-forms triggers preexisting world knowledge as well as knowledge of any associated words or concepts related to that word. For example, when the word "tuxedo," is encountered in a text, the cognitive processes that are attempting to make sense of the text do not just access it as "a formal suit of clothing." All related concepts in the memory are activated. People remember that tuxedos are expensive, that they are worn infrequently, they are uncomfortable, they can be rented, they are often worn at weddings and so on (Willingham, 2006:2 3). Limited vocabulary may prevent students from activating the relevant content schemata, which in turn may have a negative effect on their listening performance.

Vocabulary activities at the preparations stage, therefore, have three main objectives: (a) to familiarize the learners with the meaning and the form of new words, (b) to help learners recognize lexical items in the strings of connected speech, (c) to promote productive usage of the target words necessary for the reconstruction stage.

Considering the limited time that can be devoted to explicit vocabulary instruction, it is important to select activities that will promote the aspects of the word knowledge outlined above, while not taking time away from the main objective of the lesson - listening comprehension. Collocation-based lexical instruction seems to be an effective way of achieving this goal. One activity that was found to be effective is a Collocation Crossword. The students are given a list of the target words with example sentences and definitions. After that, they are asked to complete a crossword where the clues are collocates that go with the target words. For each target word, two sentences are given. To facilitate retention, typical collocates should be highlighted. Here is one example from the Model Lesson:

It is a custom that someone water over a guest's hands. I___ wine into your glass by mistake. (*Target word: to pour)

This activity promotes four different aspects of word knowledge: written and spoken form, meaning, grammar and collocates. In order to fill in the gaps, the learners must recall the meaning of the target words. As some sentences require different inflectional forms, learners also have to think about grammatical properties of the words. Highlighted collocates give typical examples of the usage of the target words. In order to complete the crossword, the students have to pay attention to spelling. Finally, an in-class check of the students' answers gives the teacher an opportunity to correct possible pronunciation errors and draw students' attention to how the target words may sound in the stream of fast connected speech allowing learners to acquire pronunciation, stress and intonation patterns.

\subsection{Listening procedure}

When the dictogloss procedure is first introduced, learners may need to hear the recording several times. The first time, the students are not permitted to take notes or write anything. They only listen to get a general idea about the text. The second time they can take notes. As inexperienced learners tend to try to write down everything, teachers should emphasize that they should focus on key words only that will help them with the reconstruction of the text. (These are often the words that were introduced in the preparation stage). A third listening gives learners a chance to confirm the information and revise their notes if necessary. A short 5-minute break between the second and the third listening gives students a chance to discuss their notes and identify the points they need to focus on. As learners get used to the procedure and their listening comprehension improves, it may be sufficient to only play the recording twice.

\subsection{Reconstruction}

Reconstruction is the central part of the dictogloss listening lesson. Working in small groups (3-4 people), students discuss what they heard and attempt to produce a coherent text close in content and organization to the original version. Limiting the group size is important to allow for individual contributions to be incorporated into the group effort (Wajnryb, 1990). The groups reconstruct the text in writing. The purpose is not to replicate the original text, but to maintain its informational content. One person is "the recorder" and the text is produced from the pooled information of the group members. In order to enforce the target vocabulary and ensure that the main points are included, students are asked to use all the words from the preparation stage.

During reconstruction, the teacher's role is to monitor the activity. No language input should be provided during this stage. There are several things, however, that the teacher can do to make the reconstruction process easier for the students. For example, enlarged copies of the lecture script may be posted around the room. One member from each group can check the script and then go back to the recorder to report what information was missing. Another student may go to another group to ask for missing information or clarification. When gathering information, students should not write anything nor have the written reconstruction with them. All information should be exchanged orally. 
During reconstruction, teacher should also observe the nature of group interaction to ensure that all students participate and that the more advanced students do not dominate the group. They should encourage silent students and adjust the timing if necessary.

\subsection{Analysis and correction}

The last stage of the dictogloss procedure is the analysis and correction of the learners' texts. In a dictogloss listening class, the main purpose of the analysis and correction stage is to identify the problems students had with text comprehension. Therefore, although the reconstruction task requires writing ability, spelling mistakes should be less of a concern. One well-recognised characteristic of language processing is that learners tend to remember the content of the message rather than the exact words used (Sachs, 1967). The reconstruction task asks students to use their language ability to put words in the meaningful units. In that process, higher-ability students are likely to replace the words from the original text with their own synonyms. These ideas should be marked as being correct. However, in order to facilitate the acquisition of new vocabulary, students should get points for using the words from the preparation stage.

Correction can be done as a class or as group work. One option is to select 1-2 recorders to read what they wrote for each section / paragraph and then compare it to the original text. Another option is to give the students the transcripts of the recording and have them swap their reconstructions with another group and then ask them to give feedback on accurate/inaccurate or missing information. Instead of a transcript, teachers may want to give students a Reconstruction Checklist. (See a sample in the Appendix.) In the list, the students are asked to check whether all target words have been used and whether all ideas have been included in the reconstruction. For each idea students are given an option of fully included, partially included or not included at all carrying 1 point, 0.5 points and 0 points respectively. Students can be asked to check their reconstruction (self-assessment) or the reconstruction of another group (peer-assessment). Students could be assigned parts of the text to check, or one student could be appointed as a "Checker" for the whole passage. The advantage of using a Reconstruction Checklist is that students get immediate feedback on their performance. Feedback is essential for language learning. As Ur (1998) observes, unlike reading and writing assignments which can tolerate delayed feedback, for listening it is essential that learners get feedback on their performance while what they have heard is still echoing somewhere in their mind, and there is still a possibility of hearing it again. Immediate feedback enables students to understand their mistakes and to learn from them. They can clearly see which vocabulary items or ideas are missing and group work provides assistance to members who have difficulty comprehending the content. The fact that the dictogloss task has very specific outcomes makes it easier for students to evaluate their success. Having the students calculate their points and fill in the progress chart (See a sample in the Appendix) allows students to monitor their progress. As the students' performance usually gets better with practice, increased perceived achievement is likely to have a positive effect on student motivation. This is important because a lack of perceived linguistic improvement can significantly reduce students' motivation.

The teacher's job is to make sure that peer feedback is correct and to provide additional linguistic guidance if necessary. By circulating among the groups, the teacher can observe and interact with a greater number of students and assist them with the problems they may encounter with the language or the content. In addition to linguistic feedback, the teacher could also discuss with the students how interaction among group members could be modified to make it more effective.

\section{Follow-up activities}

The dictogloss procedure offers various opportunities for follow-up activities. As in the original Wajnryb procedure, the teacher can compare the various versions and discuss language choices. Error analysis can help to identify grammatical points that the learners have difficulty with, which can then be further practiced. Also, if students have already studied or been exposed to particular structures that appear in the text, the reconstruction task can be used for review and self-correction.

The recordings can also be used as a basis for further discussion or written assignments. Learners may be asked to infer information about the speaker, evaluate the strength of his/her arguments, give their opinions on the information in the passage or share their experiences on matters related to the topic. For example, the Sample Lesson in the Appendix lends itself well to a discussion of table manners around the world, which can be further expanded to good manners in general, business manners and possible cultural misunderstandings that may result from the differences.

Another way of encouraging students to share their opinions is to have them insert their ideas at various points in the text (Jacobs \& Small, 1993). This type of exercise promotes a kind of dialogue between the learners and the original authors of the text.

\section{Advantages of the dictogloss method}

The dictogloss model offers several potential advantages over other models of teaching listening comprehension.

First, the dictogloss method is an effective way of combining individual and group activities. Students listen and take 
notes individually and then work together to reconstruct the texts. The reconstruction task gives students focus and a clear objective, which is a pre-condition for effective groupwork. Students are actively involved in the learning process and there are multiple opportunities for peer learning and peer teaching. After the teacher provides a framework for understanding the passage by explaining the background information, cooperative groups can develop more appropriate comparisons or examples that will assist learners with their comprehension (Thornton, 1999).

Second, the dictogloss procedure facilitates the development of the learners' communicative competence. Students' speaking time is significantly longer than in a traditional teacher-centered classroom. At the same time, the pressure to reconstruct the text within the time limit also means that students are more likely to use time effectively. Furthermore, unlike in a typical discussion class where students are presented with a list of topics or discussion questions and communication activities often have a simple question-and-answer format, in a dictogloss class, students' interaction is much more natural. A collaborative reconstruction task gives learners the opportunities to practice and use all modes of language and to become engaged in authentic communication. There is more turn-taking and students are more likely to use confirmation and clarification strategies. The variety of interaction was found to be more productive in terms of language development than the actual linguistic forms used (Wills \& Wills, 1996). As Long and Robinson (1998) point out, people learn languages best not by treating them as an object of study, but by experiencing them as a medium of communication.

Third, the reconstruction stage helps students try out their hypotheses and subsequently to identify their strengths and weaknesses. A reconstruction task encourages students to consider the input more closely. Noticing is known to be one of the crucial elements of the language learning process (Ellis, 1995). The reconstruction and correction stages help the students to compare input to their own representation of the text and to identify the possible gaps. It is through this process of cognitive comparison that new forms are incorporated, students' language competence improves and students' interlanguage is restructured.

The dictogloss procedure also promotes learners' autonomy. Students are expected to help each other recreate the text rather than depend on the teacher to provide the information. The analysis and correction stage enables the students to see where they have done well and where they need to improve. Students gain insights into their linguistic shortcomings and also develop strategies for solving the problems they have encountered.

Dictogloss also offers a unique blending of teaching listening comprehension and the assessment of students' listening ability. Traditional tests formats such as true or false items, multiple choice or open-ended questions are often not sensitive enough to capture the specific problems that learners may have at different levels of the meaning comprehension process. They typically allow only a relatively small number of selected items to be tested (e.g. main ideas, lexical items, and so on) while the rest of the text remains uncovered. If we look at a test as a diagnostic tool, then more detailed information about learners' understanding at different stages of the comprehension process is necessary. For the dictogloss task, learners need phonemic identification, lexical recognition, syntactic analysis and semantic interpretation. The reconstruction task offers an insight into the students' performance at all stages of the speech perception process. With the checklist that follows both teachers and learners can verify whether or not learning is taking place, and can identify the parts of the text and specific words or structures that cause miscomprehension. Furthermore, the nature of the reconstruction task forces students to listen carefully to other students' input, providing additional opportunities for listening practice.

The reconstruction task also promotes the acquisition of L2 vocabulary. Students need to recall the meaning and the written form of vocabulary items introduced at the preparation stage. In addition, by asking students to use new words to form complex sentences, teachers can direct the learners' attention to collocations and usage restriction in the target language.

Another advantage of the dictogloss approach is that reconstruction tasks can raise students' awareness of rhetorical patterns in the target language. Generic and rhetorical patterns are often culture specific (Kaplan, 1966). Reconstruction tasks facilitate students' ability to understand and manipulate the patterns of textual organization and make them more sensitive to discourse markers and other cohesive ties in the language they are trying to acquire.

Finally, working in small groups reduces learners' anxiety as they have to perform only in front of "a small audience." This approach may be particularly suitable for those cultures in which students tend to be reticent and are not used to voicing their ideas in front of the whole class. In Japan, for example, students are often shy and group conscious. They feel insecure about their English ability and rarely volunteer their answers. They seldom initiate conversation, generally avoid bringing up new topics and rarely seek clarification (Burrows, 1996). When asked a direct question by a teacher, an individual student will often turn to her peers and seek advice before producing a response. Students feel more relaxed and confident when they share ideas that represent a group rather than themselves only. Group interaction is also important for the feedback stage. Peer feedback can either draw students' attention to gaps in their language knowledge or provide confirming feedback which consolidates that knowledge (Storch, 1998), while eliminating the students' fear that they will be "punished" for the mistakes they have made. In short, the dictogloss approach helps 
students put aside affective factors and therefore may be suited for collectivist countries such as Japan or Korea, where students' shyness is a common problem.

\section{Implementing the dictogloss approach}

While the dictogloss method offers many advantages, there are three important issues that teachers need to be careful about with regard to its implementation. The first one is related to the socio-cultural context of the learners. The second one concerns work-group composition and dynamics. The third concern is related to student assessment.

In order for the dictogloss approach to be implemented effectively, it is important that learners recognize the benefits of collaborative learning. No-curriculum can be learner-centered unless the learners' subjective needs and perceptions about the learning process are taken into account (Nunan, 1988). If students do not feel that the curriculum and methodology match their needs, they are likely to feel frustrated. Instruction that violates the learners' preferred learning style will be of little value to them in the long run and offers the potential for conflict between the learners and the teacher (Wajnryb, 1990). In some cultures (e.g. Japanese, Korean or Chinese) students are used to having teacher-centered classes and they do not always perceive peer interaction as useful for their learning. Expectations of autonomous learning and student independence are very different from the pedagogical traditions of these countries. In these cultures, students expect to follow the teacher at all stages of the learning process. When students who are used to teacher-centered teaching practices are asked to work independently, they are often concerned about their errors not being corrected and their language not improving because of the limited time they spend talking to the teacher. The implementation of collaborative learning will not automatically motivate students or instigate a feeling of the responsibility being on them to develop their communicative competences. A mismatch between students' expectations on the one hand, and curricular content and pedagogical approaches on the other, is likely to result in student dissatisfaction with the teaching method and can significantly reduce student motivation. Therefore, it is imperative that students' expectations and beliefs about learning are not ignored. Teachers must provide a clear rationale for the methodology based on different teaching traditions. In order to make cooperative learning work, it is important that teachers explain the concepts behind it, provide the rationale underlying the selection of the particular task and increase students' awareness of the benefits of independent learning. In the case of the dictogloss procedure, this means making learners recognize that they have mutual goals. The teacher should remind the learners that the focus of the reconstruction task is not grammatical accuracy, but recall of the content, something they can help each other with. It should also be pointed out that with a transcript and the checklist, learners can easily confirm the points they have missed. While this may not always eliminate the effects of cognitive and socio-cultural factors, their effect may be minimized. If the students understand the reasons behind the activity and the value of what they are doing, their motivation to participate is likely to increase.

Another issue of concern is work-group composition and group dynamics. Cooperative learning means that students work together to accomplish shared goals. They are given two responsibilities: to maximize their own learning and to maximize the learning of all other group members (Johnson \& Johnson, 1999a). Research (e.g. Dishon \& O'Leary, 1984; Johnson \& Johnson 1989) shows that heterogeneously grouped teams bring more benefits than homogeneously formed teams. Due to differences in background and in ways of learning different people tend to attend to different information in the discourse (Gardner, 1999). This difference in perspectives means that members can learn from each other and learn to appreciate the value of diversity. As a result of this interaction they can subsequently perform better as individuals. When students have to explain material to others, they engage in higher-level processing of the material. Joint efforts to achieve mutual goals have also been found to promote higher self-esteem, productivity and critical thinking (Johnson \& Johnson, 1999a).

However, not all students perceive cooperative learning as effective and useful. Simply placing students in groups and telling them to work together does not automatically result in cooperative efforts (Johnson \& Johnson, 1994). Teachers should also not assume that students will know how to work effectively in groups. Positive interdependence is not likely to happen on its own; it must be built into the learning task. Some students may lack confidence in their English ability and consequently be reluctant to participate in group interactions; other students may try to dominate the group. Therefore, it is crucial that instructors pay sufficient attention to group dynamics and ensure that positive learning climate is maintained. Careful preparation and management are necessary.

One factor that may have a strong impact on group dynamics is students' ability. Research has shown (e.g. Zigmond \& Baker, 2002) that peer-coaching is the most common strategy teachers adopt to help weaker students. Instructors, however, are not always aware that this may cause discomfort and resentment on the part of stronger students. Matthews (1992) in his study on the attitudes of gifted students towards cooperative learning found out these often had negative reactions to working in cooperative groups. The students felt frustrated because they thought that weaker students were not listening to them and they also resented having the time taken from their own learning. They were often concerned about the quality and the grades, and therefore inclined to do all the work themselves. However, the students' attitudes changed when they were placed in more homogeneous groups with their intellectual peers. They felt 
more relaxed because they did not have to do all the work and they felt it was like "a friendly competition". In L2 contexts, implementing cooperative learning is even more difficult due to students' limited ability to express themselves in the target language. Storch (1998) claims that learners with different proficiency levels approach reconstruction tasks differently. In her study, the intermediate students tended to work on the task on a word-by-word basis while the more advanced students considered the entire sentence, and relationships between ideas in the text. In groups where the students were approximately of the same level of proficiency, all members of the group participated in the task, while in the mixed-level groups more proficient learners tended to monopolize the conversational interactions.

These findings suggest that heterogeneous and homogeneous group work should be allowed. Completely free choice groups, however, should be discouraged to prevent students from always choosing the same partners. Creating gender diverse groups is also important, as gender diversity was also found to improve group performance (Maznevski, 1994). When opting for heterogeneous groups, teachers should spend some time on team building activities, because as Slavin (1995) notes, the combination of students that result from teacher-selected groups is likely to be the one that would almost never have been created without the teacher's intervention. Teachers should facilitate the learning process by helping learners develop social skills such as decision making, trust-building and conflict management skills (Johnson \& Johnson, 1999a). Students should learn how to accommodate differences in ability, so they can support each other and benefit from the various skills they have, but stronger students should not be forced to work with weaker ones or coach them. One way to achieve group heterogeneity in an unintrusive way is simply to ask students to make groups with students they have not worked with before or make a rule that they cannot work with the same student more than once a month. It is also important that the teacher ensures that every student gets to be a recorder.

Finally, the students need to be reassured that assessment of their work will be fair. The assessment should emphasize the individual accountability of each member. It is important that students understand they cannot get "a free ride" on the work of others, but also that they will not be penalized for other students' low level of performance. One criterion for student assessment can be their cooperative skills - how much they contribute to the group, whether they assist other students in meaningful and productive ways, and so on. While the students work on reconstruction, the teacher collects data about the quality of explanations, interaction patterns among group members, students' social skills, efforts to work together cooperatively, reasoning processes and problem solving strategies. The teacher then provides feedback and coaching. As Johnson and Johnson (1999b:168) point out, cooperative learning groups can be seen as "...windows into students' minds". In this respect, the dictogloss approach offers a significant advantage compared to other, more traditional listening comprehension tasks. Students' answers on a conventional test or homework assignments tell teachers very little about students' reasoning processes and understanding. The dictogloss allows teachers to go "deep" into students listening comprehension and evaluate how well students can absorb and sort the content they hear. It provides an environment in which assessment becomes a part of the learning process. Students learn almost as much from assessing their own work and their classmates' work as they do from completing the reconstruction task. Another way of assessing students' work is by asking them to keep a journal where they discuss and reflect on their learning experiences. Journals allow both teachers and learners to verify whether learning is taking place and also to identify the elements in the procedure that may need to be adjusted. Regardless of which assessment method is adopted, it is vital that assessment criteria are clearly explained to the students.

\section{Conclusion}

The dictogloss method combines conventional teaching procedures such as topical warm-up, explicit vocabulary instruction and possibly grammar correction with a new type of meaning-based listening activity and cooperative learning. A dictogloss listening class embodies several important principles of language learning such as learner autonomy, cooperation among learners, focus on meaning and self and peer-assessment. Process is equally as important as product. The procedure entails both language decoding (dictation) and its encoding (reconstruction) and, as a result, enhances both students' listening and communication skills. It pushes learners to produce a meaningful and accurate text and to reflect on their choices. The task provides students with a sense of achievement and personal accountability and encourages them to think about the process of language learning and how to approach it more effectively. In short, if implemented correctly, the dictogloss approach results in active involvement of the students and offers a challenging and rewarding learning experience.

\section{References}

Buck, G. (2001). Assessing Listening. Cambridge: Cambridge University Press.

Burrows, C. (1996). An evaluation of task-based learning (TBL) in the Japanese classroom. English Today 24 (4): 11-16.

Chaudron, C. and Richards, J. C. (1986). The effect of discourse markers on the comprehension of lectures. Applied Linguistics, 7 (2): 113-127.

Chiang, C.S. and Dunkel, P. (1992). The effect of speech modification, prior knowledge, and listening on EFL lecture 
training. TESOL Quarterly, 26 (2): 345-374.

Dishon, D. and O'Leary, P. W. (1984). A Guidebook for Cooperative Learning: A Technique for Creating More Effective Schools. Holmes Beach, FL: Learning Publications.

Dunkel, P. and Davis, J. N. (1994). The effects of rhetorical signally cues on recall. In Flowerdew, J. (Ed.), Academic listening: research perspectives. Cambridge: Cambridge University Press.

Ellis, R. (1995). Interpretation tasks for grammar teaching. TESOL Quarterly 29 (1):87-105.

Feyten, C. (1991). The power of listening ability: an overlooked dimension in language acquisition. The Modern Language Journal, 75 (2): 173-180.

Gardner, H. (1999). Intelligence reframed: Multiple intelligences for the $21^{\text {st }}$ century. New York, NY: Basic Books.

Jacobs, G. and Small, J. (2003). Combining dictogloss and cooperative learning to promote language learning. The Reading Matrix 3 (1): 1-15.

Johnson, D. W. and Johnson, R.T. (1989). Cooperation and Competition: Theory and Research. Edina, MN: Interaction Book Company.

Johnson, D.W. and Johnson, R. T. (1994). Cooperative learning in the second language classes. The Language Teacher, 18 (10): 4-7.

Johnson, D.W. and Johnson, R. T. (1999a). What makes cooperative learning work. In Kluge, D. McGuire, S., Johnson, D. and Johnson, R. (Eds.), Cooperative Learning (pp. 23-36). Japan: JALT Applied Materials.

Johnson, D.W. and Johnson, R. T. (1999b). Cooperative learning and assessment. In Kluge, D., McGuire, S., Johnson, D. and Johnson, R. (Eds.), Cooperative Learning. (pp. 163-178). Japan: JALT Applied Materials.

Kaplan, R. B. (1966). Cultural thought pattern in inter-cultural education. Language Learning, 16 (1): 1- 20.

Kintsch, W. (1977). Memory and cognition. US: John Wiley \& Sons.

Lim, W.L. and Jacobs, G. M. (2001). An analysis of students' dyadic interaction on a dictogloss task. ERIC Document Reproduction Service No. ED 456649.

Long, M.H. and Robinson, P. (1998). Focus on form: Theory, research and practice. In Doughty C. and Williams, J. (Eds.), Focus on form in classroom language (pp. 15-41). Cambridge: Cambridge University Press.

Matthews, M. (2002). Gifted students talk about cooperative learning. In Abbeduto (Ed.), Issues in Educational Psychology (pp. 305-309). US: McGraw- Hill.

Maznevski, M. (1994). Understanding our differences. Human Relations, 47 (5): 531-552.

Mewald, C., Gassner, O. and Siggott, G. (2007). Testing Listening Specifications for the E8-Standards Listening Tests. LTC Technical Report 3. [Online] Available: http://www.uni-klu.ac.at/ltc/downloads/LTC_Technical_Report_3.pdf (October 10, 2009).

Nabei, T. (1996). Dictogloss: Is it an effective language learning task? Working Papers in Educational Linguistics, 12 (1): 59-74.

Nattinger, J.R. and DeCarrico, J.S. (1992). Lexical Phrases and Language Teaching. Oxford: Oxford University Press.

Nunan, D. (1988). The learner-centered curriculum. Cambridge: Cambridge University Press.

Olsen, L. A. and Huckin, T. N. (1990). Point-driven understanding in engineering lecture comprehension. English for Specific Purposes, 9: 33-47.

Rumelhart, D. E. (1980). 'Schemata: the building blocks of cognition.' In Spiro, Bruce \& Brewer (Eds.), Theoretical Issues in Reading Comprehension (pp. 33-58). Hillsdale, NJ: Erlbaum.

Sachs, J.S. (1967). Recognition memory for syntactic and semantic aspects of connected discourse. Perception and Psychophysics, 2: 437-442.

Slavin, R. E. (1995). Cooperative learning: Theory, research, and practice. Englewood Cliffs, NJ: Prentice Hall.

Storch, N. (1998). A classroom-based study: Insights from a collaborative reconstruction task. ELT Journal, 52 (4): 291-300.

Swain, M. \& Lapkin, S. (1998). Interaction and second language learning: Two adolescent French immersion students working together. The Modern Language Journal, 82: 320-337.

Swain, M. \& Miccoli, L. S. (1994). Learning in a content-based, collaboratively structured course. The experience of an adult ESL learner. TESL Canada Journal 12 (1): 15-28.

Thornton, P. (1999). Reading together. In Kluge, D. McGuire, S., Johnson, D. and Johnson, R. (Eds.), Cooperative 
Learning (pp. 95-105). Japan: JALT Applied Materials.

Ur, P. (1998). Teaching Listening Comprehension. UK: Cambridge University Press.

Wajnryb, R. (1990). Grammar dictation. Oxford: Oxford University Press.

Widdowson, H.G. (1983). Learning Purpose and Language Use. Oxford: Oxford University Press.

Willingham, D. T. (2006). How knowledge helps. [Online] Available: http://www.aft.org/pubs-reports/american_educator/issues/spring06/willingham.htm (June 6, 2008)

Willis, J. and Willis (1996). Challenge and change in language teaching. Oxford: Heinemann.

Zigmond, N. and Baker, J.M. (2002). Full inclusion for students with learning disabilities. In Abbeduto (Ed.), Issues in Educational Psychology (pp.74-86). US: McGraw- Hill.

\section{Appendix (Sample Lesson)}

(Preparation Stage)

Warm-up Discussion

Instructions: Work in pairs or small groups and discuss the questions below.

1.What kind of food do you like?

2. How healthy are your eating habits?

3. Do you prefer to eat out or at home?

4. What is the most unusual food you have tried?

5. Do you like ethnic food?

6. What do you know about eating and drinking habits in Muslim countries?

7. What kind of dish is couscous? Where does it come from?

What do you think today's listening will be about?

\section{Vocabulary}

1. to pour $=$ to make a liquid flow from a container in a continuous stream

$$
\text { e.g. She poured the sauce over pasta. }
$$

2. bowl $=$ a deep round dish with a wide open top used especially for holding food or liquid e.g. Could you pass me a salad bowl?

3. custom = an accepted way of behaving or of doing things in a society or a community

e.g. It is the custom in that country for women to marry young.

4. thumb $=$ the short thick finger at the side of the hand slightly apart from the other four.

Although she is eight, she still sucks her thumb when she is worried.

5. carpet $=\mathrm{a}$ thick woollen or artificial fabric for covering floors or stairs

e.g. She bought a new Persian carpet for her living room.

6. cushion $=\mathrm{a}$ fabric bag filled with soft material or feathers that is used, for example, to make a seat more comfortable e.g. She bought matching curtains and cushions.

\section{Collocation Crossword}

Instructions: Complete the crossword below with a suitable word from the list. The clues are the collocations that go with each of the target words. Sometimes you may need to change the form of the word. (*For the crossword use the basic dictionary form; i.e. the form given in the word list.)

Words: to pour bowl custom thumb carpet cushion

Across

2. Persian are hand-woven. Just because a is thicker, it doesn't mean it will last longer.

4. There are many interesting in Japan. Moroccan people observe many traditional 
5. She filled a of soup. Moroccan ceramic are famous in the world.

Down

1. I picked up the beetle carefully between finger and

He smiled and raised a in greeting.

2. In a Middle-Eastern room you can see many floor of the sofa.

3. It is a custom that someone water over a guest's hands.

I___ wine into your glass by mistake.

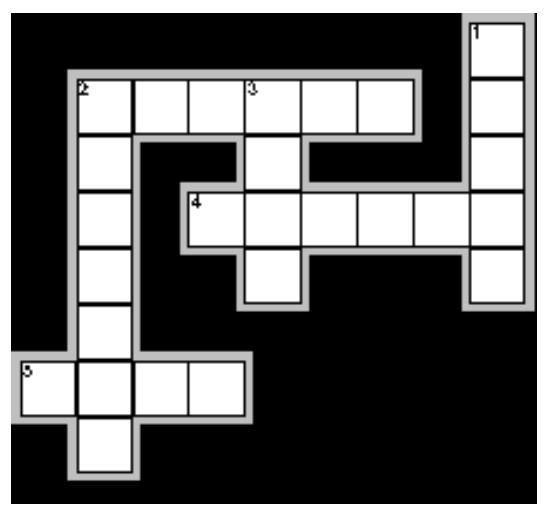

\section{Reconstruction Checklist:}

Were these words used in the reconstruction? (1 point each)

\begin{tabular}{|c|c|}
\hline bowl & [ ] \\
\hline carpet & [ \\
\hline cushion & L \\
\hline custom & {[} \\
\hline pour & {[} \\
\hline thumb & \\
\hline
\end{tabular}


Were these ideas included in the reconstruction?

\begin{tabular}{|c|c|c|c|}
\hline $\begin{array}{c}1 \text { pt } \\
\text { (fully) }\end{array}$ & $\stackrel{.5}{\text { (partially) }}$ & $\begin{array}{c}0 \\
\text { (not at all) }\end{array}$ & \\
\hline & & & $\begin{array}{l}\text { There are many interesting customs when you eat a } \\
\text { traditional Moroccan meal. }\end{array}$ \\
\hline & & & You eat in a room with cushions and pillows... \\
\hline & & & .....and thick carpets on the floor. \\
\hline & & & The food is on low tables. \\
\hline & & & Before you sit down, you should shake hands with everyone. \\
\hline & & & Start with a person on your right... \\
\hline & & & .....and go around the room. \\
\hline & & & You need to wash your hands. \\
\hline & & & Hold hands over a big bowl.... \\
\hline & & & while someone pours water over them. \\
\hline & & & Before anyone can eat, the host says Bismillah..... \\
\hline & & & ...which means "Praise be to God" \\
\hline & & & The host serves the foods in a certain order. \\
\hline & & & Moroccan food is famous for its stews of meat or fish.... \\
\hline & & & ....cooked with fruits or vegetables. \\
\hline & & & The most famous food is couscous.... \\
\hline & & & .... a dish cooked in a spicy sauce. \\
\hline & & & People usually have water to drink. \\
\hline & & & $\begin{array}{l}\text { You eat with your thumb and first three fingers of your right } \\
\text { hand. }\end{array}$ \\
\hline & & & After eating you wash your hands again. \\
\hline & & & Everyone enjoys a cup of mint tea. \\
\hline
\end{tabular}

TOTAL: 127

Transcript

There are many interesting customs when you eat a traditional Moroccan meal. Now, generally, you eat in a room with cushions and pillows and thick carpets on the floor. The food is on low tables.

Before you sit down, you should shake hands with everyone. You should start with the person on your right and go around the room. Next, you need to wash your hands. You hold them over a big bowl while someone pours water over them. Before anyone can eat, the host says Bismillah, which means "Praise be to God."

Your host serves the foods in a certain order. Moroccan food is famous for its stews of meat or fish cooked with fruits or vegetables. Of course, the most famous food is couscous, a dish cooked in a spicy sauce. People usually have water to drink.

At a Moroccan table, you eat with your hand. You should use your thumb and your first three fingers of your right hand. After eating you wash your hands again. Finally, everyone enjoys a cup of mint tea together.

(from: Leo Jones (2001). Let's Talk 1 (C) Cambridge University Press - reproduced by permission) 